Acta Cryst. (1953). 6, 827

\title{
Change of Structure of Ferrous Oxide at Low Temperature*
}

\author{
By B. T. M. WIIlis and H. P. RooksBy \\ Research Laboratories of The General Electric Company Limited, Wembley, England
}

(Received 28 May 1953)

\begin{abstract}
The structure of ferrous oxide has been studied between room temperature and liquid-air temperature $\left(90^{\circ} \mathrm{K}\right.$.) by X-ray powder photography. The results support the conclusion of Jette \& Foote that at room temperature the structure is of the $\mathrm{NaCl}$-type with a small and variable number of the $\mathrm{Fe}^{2+}$ sites vacant, so that the stoichiometric composition $\mathrm{FeO}$ is never attained.

At low temperature (below $200^{\circ} \mathrm{K}$.) the structure is rhombohedral, the new structure cell being derived from the originally cubic cell by an extension along one of the triad-axis directions. This is a change of the second order and appears to be directly connected with the transition from the paramagnetic to the antiferromagnetic state on cooling through $198^{\circ} \mathrm{K}$. The magnitude of the change, as measured at liquid-air temperature, is very sensitive to the concentration of iron in the oxide. Thus, for the oxide of minimum iron content the rhombohedral angle $\alpha$ at $90^{\circ} \mathrm{K}$. is within one minute of the value $\left(60^{\circ}\right)$ which corresponds to cubic symmetry, whereas $\alpha$ is $59^{\circ} 23^{\prime}$ for the least iron-deficient oxide.

It is shown that the powder photograph taken at liquid-air temperature provides a much more sensitive indication of the degree of homogeneity of the sample than that taken at room temperature.
\end{abstract}

\section{Introduction}

The variable composition of ferrous oxide has been known for some time, but the origin of this variation has received various interpretations from different authors. From an investigation of the chemical composition, room-temperature lattice parameter, and density of oxides of different composition, Jette \& Foote $(1933 a, b)$ concluded that at room temperature the structure is of the NaCl-type with a small and variable number of the $\mathrm{Fe}^{2+}$ sites vacant. Bénard (1937, 1939), however, measured the lattice parameters of various oxide preparations and obtained quite different results (the two sets of results are discussed below in $\S 3$ ). He concluded that oxides of minimum iron content correspond to stoichiometric $\mathrm{FeO}$, and that oxides of higher iron content contain the excess iron in interstitial solid solution. The present state of our knowledge has been recently reviewed by Wyckoff (1952), who says: 'When ferrous oxide is heated with an excess of iron and quenched from a series of temperatures, the lattice parameter is greater the higher the quenching temperature. This has been interpreted to mean that at elevated temperatures iron dissolves in and swells the ferrous oxide structure: it could also represent an attempt to complete the lattice by approaching the $1: 1$ composition ratio.'.

The main part of the present investigation is concerned with the low-temperature structure of ferrous oxide. In addition, certain observations on the room-

* Communication No. 554 from the Staff of the Research Laboratories of The General Electric Company Limited, Wembley, England. temperature structure are given, as they have an important bearing on the discussion of the low. temperature measurements, and, moreover, help to resolve the disagreement between the results of Bénard and of Jette \& Foote.

\section{Preparation of oxides of different composition}

Ferrous oxide is unstable below $570^{\circ} \mathrm{C}$. and decomposes according to the equation

$$
4 \mathrm{FeO}=\mathrm{Fe}_{3} \mathrm{O}_{4}+\mathrm{Fe} .
$$

The velocity of this reaction attains a maximum at $500^{\circ}$ C. (Bénard \& Chaudron, 1936), but is very small at room temperature. Consequently, ferrous oxide samples must be prepared above $570^{\circ} \mathrm{C}$. and then rapidly quenched to room temperature. It is desirable to carry out X-ray examinations soon after the quenching process, in order to avoid ambiguities arising from partial decomposition of the metastable ferrous oxide preparations.

Approximately $20 \mathrm{~g}$. of ferrous oxide, used as the basic material $(A)$ for subsequent preparations, were prepared by decomposition of ferrous oxalate at $800^{\circ} \mathrm{C}$. in a stream of nitrogen. The product obtained after heating for $3 \mathrm{hr}$. gave an X-ray powder photograph showing lines of the ferrous oxide structure only. The preparation of the oxide from the oxalate was not used by Jette \& Foote (1933a), because they found that the product obtained by decomposition in vacuo gave lines of free iron as well as ferrous oxide on the powder photograph. In their work, the formation of free iron may have been due to reduction of the oxide by carbon monoxide according to the equations 


$$
\begin{aligned}
\mathrm{FeC}_{2} \mathrm{O}_{4} & =\mathrm{FeO}+\mathrm{CO}+\mathrm{CO}_{2}, \\
\mathrm{FeO}+\mathrm{CO} & =\mathrm{Fe}+\mathrm{CO}_{2} .
\end{aligned}
$$

We avoided this difficulty by carrying away the carbon monoxide and carbon dioxide gases in a stream of nitrogen.

The material $(A)$ was then divided into two equal portions. One portion was mixed with a small excess of iron (mixture $B$ ) and the other portion with a small excess of $\mathrm{Fe}_{3} \mathrm{O}_{4}$ (mixture $C$ ). The mixture $B$ was further subdivided into several quantities weighing approximately $1 \mathrm{~g}$. each, and each quantity was separately enclosed in a small platinum thimble and sealed in an evacuated quartz tube. The individual tubes were heated at a given temperature in the range $600-1200^{\circ} \mathrm{C}$. The duration of the heat treatment was from $2 \mathrm{hr}$. to $60 \mathrm{hr}$., depending on the temperature, and after this time the tube was quenched by rapid immersion in cold water. In this way several different samples were obtained, corresponding to ferrous oxide in equilibrium with iron at different temperatures from $600^{\circ} \mathrm{C}$. to $1200^{\circ} \mathrm{C}$.

Samples of ferrous oxide in equilibrium with $\mathrm{Fe}_{3} \mathrm{O}_{4}$ were prepared in exactly the same way from mixture $C$.

\section{Room-temperature structure}

$\mathrm{X}$-ray powder photographs of each sample were taken at room temperature and liquid-air temperature $\left(90^{\circ} \mathrm{K}\right.$.) with a $19 \mathrm{~cm}$. camera using Co $K \alpha$ radiation. For sintered specimens care was taken in powdering to avoid introducing excessive lattice distortion. X-ray photographs of these specimens gave sharp high-order lines.

The room-temperature lattice parameter $\left(a_{0}\right)$ of each sample was determined to an accuracy of $\pm 0.0003 \AA$

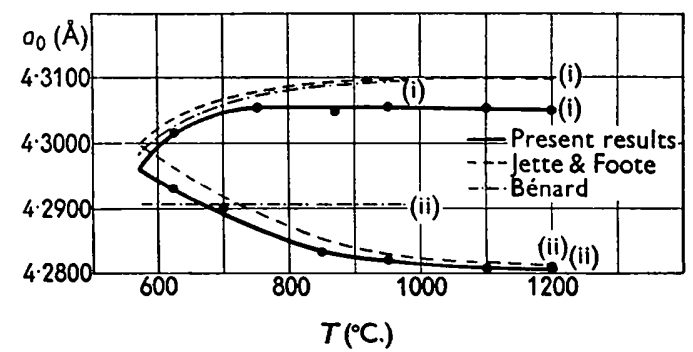

Fig. 1. Curves showing relation between $a_{0}$ and the quenching temperature, $T$, for ferrous oxide heated in presence of (i) $\mathrm{Fe}$, (ii) $\mathrm{Fe}_{3} \mathrm{O}_{4}$, according to different authors.

by means of the usual extrapolation methods, and the results are given in Fig. 1, in which $a_{0}$ is plotted against $T$, the temperature from which the sample was quenched. Curve (i) refers to the samples of ferrous oxide heated in the presence of free iron and curve (ii) to the samples heated with $\mathrm{Fe}_{3} \mathrm{O}_{4}$. Determinations of the $a_{0}$ versus $T$ curve have also been carried out by Jette \& Foote $(1933 b)$ and Bénard (1939). Their results are also included in the figure after the values of $a_{0}$ have been multiplied by the factor 1.00202 , in order to express them on the same absolute scale (Co $K \alpha_{1}=$ $1.78890 \AA$ ) as the present results.

Fig. 1 shows that our results are in much closer accord with the previous observations of Jette \& Foote than with those of Bénard. In particular, we have confirmed that $a_{0}$ decreases rapidly with the increasing quenching temperature $T$ for the oxide heated in the presence of $\mathrm{Fe}_{3} \mathrm{O}_{4}$, whereas Bénard found that $a_{0}$ is independent of $T$ in the temperature range $575-975^{\circ}$ C. It was this observation that led him to conclude that ferrous oxide in equilibrium with $\mathrm{Fe}_{3} \mathrm{O}_{4}$ corresponds to stoichiometric $\mathrm{FeO}$.

It is difficult to account for the apparently anomalous results of Bénard, except on the basis of incorrect heat treatment. Unfortunately, there is no reference in his papers to the details of heat treatment of the oxide in the presence of $\mathrm{Fe}_{3} \mathrm{O}_{4}$, and only three experimental points were included on his curve (ii) (Fig. 1) referring to such oxides. We have found that, for temperatures below $900^{\circ} \mathrm{C}$., heating for a few hours only is not sufficient to give samples with a value of $a_{0}$ which corresponds to ferrous oxide in equilibrium with $\mathrm{Fe}_{3} \mathrm{O}_{4}$.

\section{Structure at liquid-air temperature}

The low-temperature structure of ferrous oxide has been previously investigated by Ellefson \& Taylor (1934), who reported that the structure remained cubic down to $160^{\circ} \mathrm{K}$. We have observed, however, a decisive structure change in ferrous oxides when cooled below c. $200^{\circ} \mathrm{K}$., and this has been briefly reported in an earlier communication (Tombs \& Rooksby, 1950).

Fig. 2(a) is a photograph of the room-temperature powder pattern (Co $K \alpha$ radiation) of the original oxide $(A)$, and Fig. $2(b)$ is the corresponding photograph taken at liquid-air temperature. The 220,311 and 420 lines are slightly broader in $(b)$ than in $(a)$, whereas the definition of the 400 line remains unchanged. This suggests that at low temperatures the cubic structure cell is deformed very slightly along a [111] direction to give a rhombohedral cell, and this interpretation is completely verified by observations on oxide samples in which the iron concentration is higher.

The X-ray photographs of Fig. 2(c) and (d) represent results on a specimen of ferrous oxide obtained by heat treatment of oxide $(A)$ in the presence of free iron at $900^{\circ} \mathrm{C}$. It will be seen that the 220 and 420 lines of Fig. 2(c) have each been split into two lines of approximately the same intensity in Fig. $2(d)$, and the 331 line into three lines of which the two lower-angle lines are relatively weak. The 400 line remains unsplit. This form of powder pattern is that expected for a change from a cubic to a rhombohedral structure cell by extending the cubic cell along a [111] direction. 

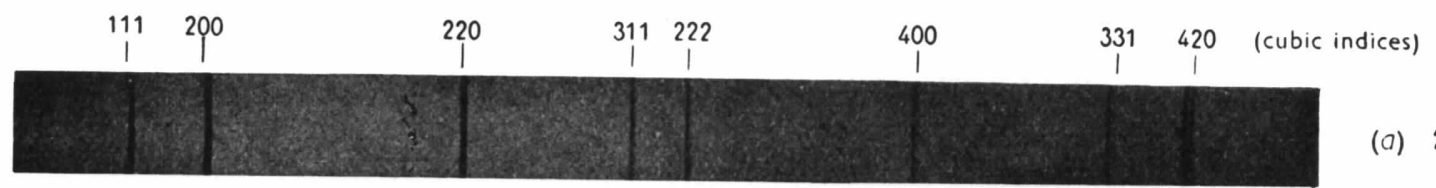

(a) $290^{\circ} \mathrm{K}$

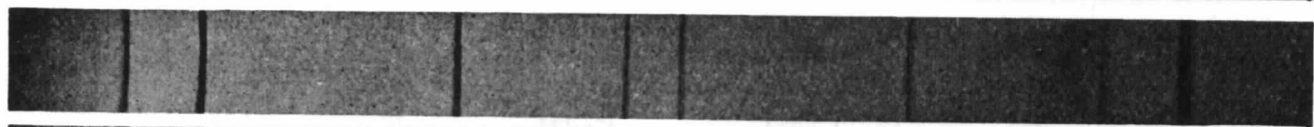

(b) $90^{\circ} \mathrm{K}$.

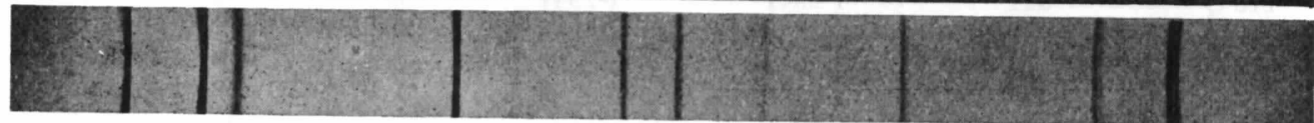

(c) $290^{\circ} \mathrm{K}$.

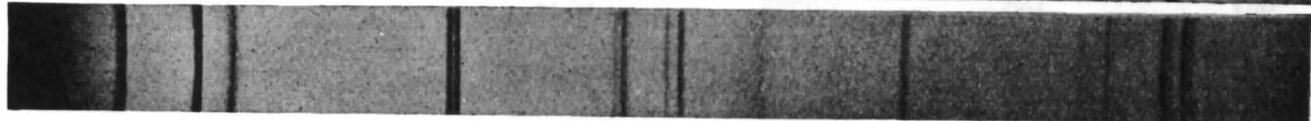

(d) $90^{\circ} \mathrm{K}$
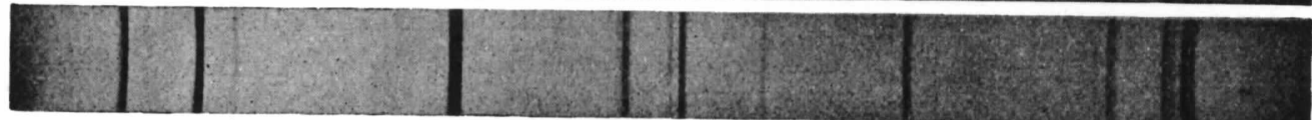

(e) $90^{\circ} \mathrm{K}$

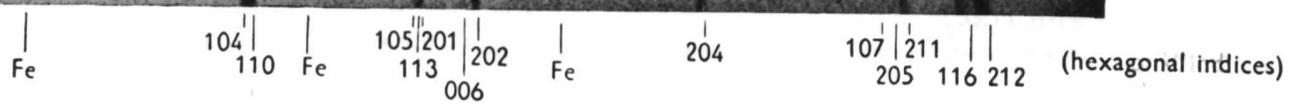

Fig. 2. X-ray powder photographs of different samples of ferrous oxide taken at liquid-air and room temperatures.

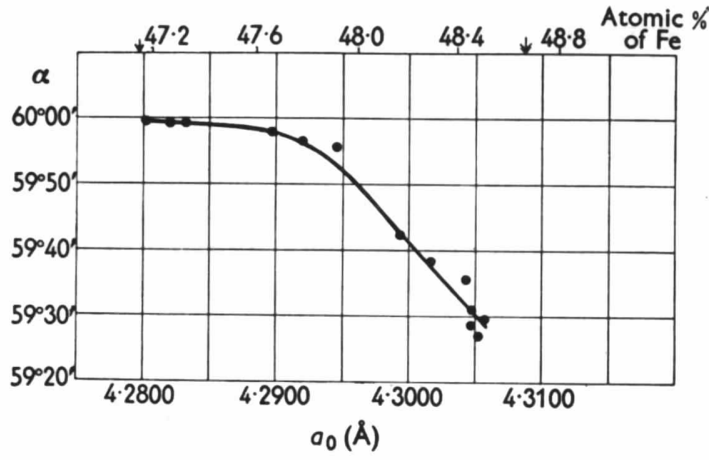

(a)

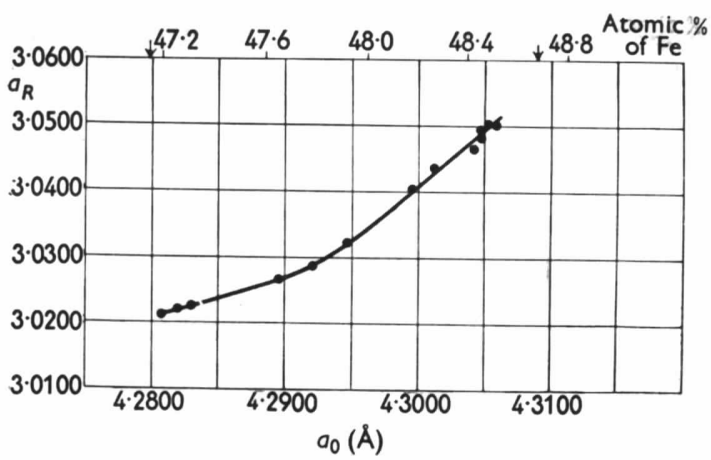

(b)

Fig. 3. (a) Relation between $\alpha$ at $90^{\circ} \mathrm{K}$. and the room-temperature value of $a_{0}$.

(b) Relation between $a_{R}$ at $90^{\circ} \mathrm{K}$. and the room-temperature value of $a_{0}$.

The rhombohedral angle $\alpha$ is therefore less than the $60^{\circ}$ required by cubic symmetry.

The observed spacings and intensities taken from the low-temperature powder pattern (Fig. $2(d)$ ) are listed in Table 1 , and compared with the values calculated by assuming a rhombohedral structure cell with lattice parameters

$$
a_{R}=3 \cdot 0499 \AA, \alpha=59^{\circ} 27 \cdot 5^{\prime},
$$

and with atomic parameters equivalent to those for the room-temperature face-centred cubic structure. Agreement between calculated and observed figures is extremely good.

Values of the rhombohedral lattice parameters $a_{R}, \alpha$ have been determined for many samples of different iron content from appropriate $90^{\circ} \mathrm{K}$. powder photographs. The results are given in the curves Fig. 3 $(a)$ and $(b)$, in which the room-temperature structure cell dimension, $a_{0}$, is plotted against $\alpha$ and $a_{R}$, respectively.
According to Jette \& Foote (1933a), $a_{0}$ increases with iron content in an approximately linear fashion, and their data have been used in Fig. 3 to express $a_{0}$ in terms of the atomic percentage of iron in the ferrous oxide structure. The two arrows on each abscissa axis indicate the limits of homogeneity of ferrous oxide as determined by the same authors (Jette \& Foote, $1933 b)$. We see from the figure that the magnitude of the cubic/rhombohedral change is relatively small for oxides containing up to $\mathbf{4 7 . 8}$ atomic $\%$ of iron, but that for oxides of higher iron content the magnitude of the change increases more rapidly. The lattice parameters of ferrous oxide at its limits of homogeneity are listed in Table 2 . These values are derived from extrapolation of the curves in Fig. $3(a)$ and $(b)$.

The two lines 116 and 212 in Fig. 2(d) are of approximately the same density. However, in Fig. 2(e), which is a photograph taken at liquid-air temperature of a different sample, 116 appears to be distinctly 
Table 1. Observed and calculated spacings and intensities (Co $\left.K \alpha_{1}\right)$ for ferrous oxide $\left(48 \cdot 5\right.$ atomic $\% \mathrm{Fe}$ ) at $90^{\circ} \mathrm{K}$.

\begin{tabular}{|c|c|c|c|c|c|}
\hline $\begin{array}{c}h k l \\
\text { (hexagonal } \\
\text { indices) }\end{array}$ & $\begin{array}{c}\text { Corresponding } \\
\text { room- } \\
\text { temperature } \\
\text { cubic indices }\end{array}$ & $d_{o}(\AA)$ & $d_{c}(\AA) \dagger$ & $I_{o}$ & $I_{c} \dagger$ \\
\hline $\left.\begin{array}{l}104 \\
110\end{array}\right\}$ & 220 & $\begin{array}{l}1.5246 \\
1.5122\end{array}$ & $\begin{array}{l}1.5248 \\
1.5124\end{array}$ & $\begin{array}{l}s \\
s\end{array}$ & $\begin{array}{l}97 \\
95\end{array}$ \\
\hline $\left.\begin{array}{l}105 \\
113 \\
201\end{array}\right\}$ & 311 & $\begin{array}{l}1 \cdot 3014 \\
1 \cdot 2941 \\
1 \cdot 2908\end{array}$ & $\begin{array}{l}1 \cdot 3018 \\
1 \cdot 2941 \\
1 \cdot 2903\end{array}$ & $\begin{array}{l}w \\
m \\
m\end{array}$ & $\begin{array}{l}21 \\
42 \\
21(+21 *)\end{array}$ \\
\hline $\left.\begin{array}{l}006 \\
202\end{array}\right\}$ & 222 & $\begin{array}{l}1 \cdot 2497 \\
1 \cdot 2366\end{array}$ & $\begin{array}{l}1 \cdot 2501 \\
1 \cdot 2365\end{array}$ & $\begin{array}{l}w \\
m\end{array}$ & $\begin{array}{l}16 \\
46\end{array}$ \\
\hline 204 & 400 & 1.0738 & $1 \cdot 0738$ & $m$ & 38 \\
\hline $\left.\begin{array}{l}107 \\
205 \\
211\end{array}\right\}$ & 331 & $\begin{array}{l}0.99179 \\
0.98663 \\
0.98157\end{array}$ & $\begin{array}{l}0.99180 \\
0.98665 \\
0.98159\end{array}$ & $\begin{array}{l}w \\
w \\
m\end{array}$ & $\begin{array}{l}20 \\
20 \\
40\end{array}$ \\
\hline $\left.\begin{array}{l}116 \\
212\end{array}\right\}$ & 420 & $\begin{array}{l}0.96364 \\
0.95733\end{array}$ & $\begin{array}{l}0.96358 \\
0.95730\end{array}$ & $\begin{array}{l}s \\
s\end{array}$ & $\begin{array}{r}95 \\
100\end{array}$ \\
\hline
\end{tabular}

\footnotetext{
* Coincidence with $113 \alpha_{2}$. $I_{212}=100$.

$\dagger$ Calculated using lattice parameters (hexagonal cell): $a_{H}=3.0248, c_{H}=7.5010 \AA$, and intensities normalized to
} $s=$ strong, $m=$ medium, $w=$ weak.

weaker than 212 , and the apparent densities of the lower-angle components of the other groups of lines are correspondingly reduced. This apparent weakening of the lower-angle components also occurred in varying degrees in low-temperature photographs of other samples.

Table 2. Lattice parameters for ferrous oxides of limiting compositions

\begin{tabular}{lcccc} 
& $\begin{array}{c}\text { Cubic cell } \\
\left(290^{\circ} \mathrm{K} .\right)\end{array}$ & \multicolumn{2}{c}{$\begin{array}{c}\text { Rhombohedral cell } \\
\left(90^{\circ} \mathrm{K} .\right)\end{array}$} \\
\cline { 3 - 4 } & $a_{0}$ & $a_{R}$ & $\alpha$ \\
Maximum iron & $4 \cdot 3088 \AA$ & $3 \cdot 0550 \AA$ & $59^{\circ} 23 \cdot 0^{\prime}$ \\
Minimum iron & $4 \cdot 2800 \AA$ & $3 \cdot 0210 \AA$ & $59^{\circ} 59 \cdot 5^{\prime}$
\end{tabular}

This effect can be explained as follows. If we consider the cubic 420 line, splitting occurs at lowtemperatures into the components 116 and 212 , whose displacements from the $\mathbf{4 2 0}$ line (after correcting for thermal contraction) differ considerably. The displacement of 116 is approximately nine times that of 212 , as the structure change on cooling takes place by an extension parallel to the rhombohedral triad axis with only a relatively small contraction normal to this axis. Thus any slight inhomogeneity of the sample, involving small local variations of lattice spacing, results in a broadening of 116 relative to 212 , and this broadening is apparent as a reduction of the peak density of the line. For the same reason an apparent reduction in density of the lower-angle components of the other groups of lines takes place. It should be emphasised that it is the apparent densities of the lower-angle components that show this anomalous behaviour. If integrated intensities had been evaluated, the anomalies would in all probability have disappeared, but no confirmatory measurements have been carried out.

The relative peak densities between components of split lines in the low-temperature powder photograph are of some practical interest. The density relationships provide a very sensitive indication of the degree of homogeneity of any given sample, an indication which is not apparent in the room-temperature photographs.

X-ray powder photographs of an oxide of high iron content were taken at the intermediate temperatures $160^{\circ} \mathrm{K}$. and $200^{\circ} \mathrm{K}$. The splitting of the cubic lines could be clearly seen at $160^{\circ} \mathrm{K}$., whereas no splitting was observable at $200^{\circ} \mathrm{K}$.

\section{Discussion of results}

It is clear from the X-ray photographs taken at different temperatures below room temperature that the change of structure of ferrous oxide, which develops on cooling through a certain transition temperature $T_{\lambda}$, is a change of the 'second order'. The change develops over an extended range of temperatures, and involves no re-arrangement of the ions within the structure cell. Similar structure changes have been observed in $\mathrm{MnO}$ and $\mathrm{NiO}$ below the temperatures $160^{\circ} \mathrm{K}$. and $470^{\circ} \mathrm{K}$. respectively (Tombs \& Rooksby, 1950; Rooksby, 1948). It must be noted, however, that the deformation on cooling ferrous oxide takes place in an opposite sense from the changes in $\mathrm{MnO}$ and $\mathrm{NiO}$, so that the rhombohedral angle is less than $60^{\circ}$ for ferrous oxide and greater than $60^{\circ}$ for $\mathrm{MnO}$ and $\mathrm{NiO}$.

The X-ray results indicate that for ferrous oxide of high iron content $T_{\lambda}$ lies between $160^{\circ} \mathrm{K}$. and $200^{\circ} \mathrm{K}$. According to Bizette (1946), the antiferromagnetic transition temperature of ferrous oxide is $198^{\circ} \mathrm{K}$., and there is strong reason for believing (Smart \& Greenwald, 1950) that the structure change is directly connected with the development of the antiferromagnetic state below this temperature. Moreover, Shull, Strauser \& Wollan (1951) have shown by neu- 
tron-diffraction observations on powdered ferrous oxide at $80^{\circ} \mathrm{K}$. that the magnetic moments of the $\mathrm{Fe}^{2+}$ ions are parallel within a given (111) sheet of $\mathrm{Fe}^{2+}$ ions and antiparallel between adjacent sheets. This picture is consistent with the X-ray observations, which indicate the development of a unique triad axis normal to a set of (111) planes.

The reason for the marked difference in the magnitude of the crystal structure change at low temperatures of ferrous oxide samples of different iron content (see Table 2) is not clear. It is unlikely that the difference is due to a variation of the transition temperature $T_{\lambda}$ between the different samples. Such an explanation would require a change of $T_{\lambda}$ of approximately $100^{\circ} \mathrm{K}$. when the iron content of the sample increases from 47.5 to 48.5 atomic $\%$, whereas the actual change in $T_{\lambda}$ for this range is probably much less. Thus Bizette (1946) found that $T_{\lambda}$ was $198^{\circ} \mathrm{K}$. for a sample of maximum iron content, and Millar (1929) that $T_{\lambda}$ was $185^{\circ} \mathrm{K}$. for a sample which was probably of minimum iron content. Further, Bizette measured the variation of $T_{\lambda}$ as a function of composition in the solid solution system $\mathrm{FeO}-\mathrm{MgO}$, and found that on lowering the atomic concentration of iron by $1 \%$ (by replacement of $\mathrm{Fe}^{2+}$ with the nonmagnetic ion $\mathrm{Mg}^{2+}$ ) a reduction in $T_{\lambda}$ of $5^{\circ} \mathrm{K}$. only took place.

It appears reasonable to expect the magnitude of the deformation below $T_{\lambda}$, which takes place in a direction normal to (111) ionic sheets, to increase as the number of vacant sites and $\mathrm{Fe}^{3+}$ ions within the sheets is reduced, i.e. as the stoichiometric composition is approached. However, on Bénard's interpretation of the room-temperature structure, the deformation is extremely small for stoichiometric $\mathrm{FeO}$ and increases rapidly as the proportion of dissolved $\mathrm{Fe}^{2+}$ ions increases. We believe that this is therefore additional evidence in favour of the interpretation of Jette \& Foote.

\section{References}

Bénard, J. (1937). C. R. Acad. Sci., Paris, 205, 912.

Bénard, J. (1939). Ann. Chim. (11), 12, 5.

Bénard, J. \& Chaudron, G. (1936). C. R. Acad. Sci., Paris, 202, 1336.

Bizette, H. (1946). Ann. Phys., Paris, (12), 1, 295.

Ellefson, B. S. \& TAYLoR, N.W. (1934). J. Chem. Phys. 2, 58.

Jette, E. R. \& Foote, F. (1933a). J. Chem. Phys. 1, 29. Jette, E. R. \& Foote, F. (1933b). Trans. Amer. Inst. Min. (Metall.) Engrs. 105, 276.

Millar, R. W. (1929). J.Amer. Chem. Soc. 51, 215.

Rooksby, H. P. (1948). Acta Cryst. 1, 226.

Shuld, C. G., Strauser, W. A. \& Wollan, E. O. (1951). Phys. Rev. 83, 333.

SmaRT, J. S. \& GREenwald, S. (1950). Nature, Lond. 166, 523.

Tomвs, N. C. \& RooksBy, H. P. (1950). Nature, Lond. $165,442$.

Wyckoff, R. W. G. (1952). Crystal Structures, vol. 1. New York: Interscience Publishers.

Acta Cryst. (1953). 6, 831

\title{
The Structure of Dimethyl Oxalate
}

\author{
By Maryon W. Dougrll and G. A. Jeffrey* \\ Department of Inorganic and Physical Chemistry, The University of Leeds, England
}

(Received 7 April 1953)

\begin{abstract}
An X-ray analysis of the crystal structure of dimethyl oxalate shows that the molecule has a planar trans-trans configuration, which is the planar structure of least steric interference. The bond lengths and valency angles are $\mathrm{C}^{1}-\mathrm{C}^{1} 1 \cdot 53 \pm 0 \cdot 08, \mathrm{C}^{2}-\mathrm{O}^{1} 1 \cdot 19, \mathrm{C}^{1}-\mathrm{O}^{2} 1 \cdot 31, \mathrm{O}^{2}-\mathrm{C}^{2} 1 \cdot 46 \pm 0.05 \AA, \mathrm{C}^{1}{ }_{-} \mathrm{C}^{1}-\mathrm{O}^{1}$ $125^{\circ}, \mathrm{C}^{1}-\mathrm{C}^{1}-\mathrm{O}^{2} 110^{\circ}, \mathrm{O}^{1}-\mathrm{C}^{1}-\mathrm{O}^{2} 125^{\circ}, \mathrm{C}^{1}-\mathrm{O}^{2}-\mathrm{C}^{2} 118^{\circ} \pm 3^{\circ}$. The intramolecular methyl to carbonyl distance is $2.70 \AA$. Of the four intermolecular distances which are less than $3.95 \AA$, three at 3.35 , 3.54 and $3.57 \AA$ correspond to co-ordination of carbonyl oxygen atoms around a methyl group very approximately in the directions of the $\mathrm{C}-\mathrm{H}$ bonds. It is suggested that there is weak association or polarization bonding between the carbonyl and the methyl groups which accounts for the anomalous melting point. This may also provide an explanation of the differences which have been reported in the Raman spectra of the solid and liquid.
\end{abstract}

\section{Introduction}

In the recent crystal-structure analyses of $\alpha$-anhydrous oxalic acid (Cox, Dougill \& Jeffrey, 1952),

\footnotetext{
* Now at Chemistry Department, University of Pittsburgh, U.S.A.
}

oxalic acid dihydrate (Ahmed \& Cruickshank, 1953), ammonium oxalate hydrate (Jeffrey \& Parry, 1952) and sodium oxalate (Jeffrey \& Parry, 1953) it was found that the configuration of the $(\mathrm{COO})_{2}$ is planar in the acids but not necessarily so in the salts. In $\left(\mathrm{NH}_{4}\right)_{2}(\mathrm{COO})_{2} \cdot \mathrm{H}_{2} \mathrm{O}$ the oxalate ion is non-planar with 